\title{
Changing Trends in the Types of Intrauterine Illicit Drug Exposures in Neonates Admitted to Our Neonatal Intensive Care Unit (NICU)
}

\section{Swosti Joshi}

Department of Neonatology, John H Stroger Jr. Hospital of Cook County, Illinois, USA

*Corresponding author: Swosti Joshi, Department of Neonatology, John H Stroger Jr. Hospital of Cook County, Illinois, USA, Tel: 630-965-2398; Email: swostijoshi@gmail.com

Received date: August 10, 2017; Accepted date: August 16, 2017; Published date: August 21, 2017

Copyright: (C) 2017 Joshi S. This is an open access article distributed under the terms of the Creative Commons Attribution License, which permits unrestricted use, distribution, and reproduction in any medium, provided the original author and source are credited.

Keywords: Illicit drugs; Maternal marijuana; Maternal opiate; Maternal cocaine; Cannabinoids

\section{Introduction}

A variety of illicit drugs abused by women during pregnancy cross the placenta. All of these may be associated with short-term deleterious effects on birth outcomes that are often drug specific. For instance, maternal cocaine use may result in catastrophic birth outcomes like placental abruption [1], maternal opiate use in neonatal abstinence syndrome and maternal cannabinoid use in preterm birth $[2,3]$. Prevalence of maternal use of specific drugs has probably shifted over the years in keeping with the popularity or access to these substances in local communities. Awareness of shifts in intrauterine illicit drug exposure patterns is important as they likely impact problems encountered in neonates admitted to NICU.

\section{Objective}

To determine the current prevalence of types of illicit drugs that neonates admitted to our NICU are exposed to in-utero and to assess if the pattern has changed over the past 10 years.

\section{Study Design}

We conducted a retrospective chart review of all neonates born in our hospital and admitted to NICU between 2005 and 2014. Each maternal and newborn electronic medical record was reviewed for evidence of substance use in pregnancy. A detailed social history is obtained and documented for all mothers and neonates. Urine toxicology test is performed in our institution in all mothers and neonates using protocol driven social and medical high-risk criteria. A positive result by any of these methods was abstracted and recorded. Pearson and Spearman correlation analysis was done to evaluate relationship between prevalence of use of cocaine and marijuana.

\section{Results}

Total of 3033 mother-infant dyad charts were reviewed. Of these, 513 mothers were reported to have substance use (cocaine, cannabinoids and opioid separately or in combination). Use of cocaine in mothers of the babies admitted in our NICU has gradually decreased whereas cannabinoid has increased (correlation coefficient -4.70 with $p$ value $=0.11$ ). Since it is a retrospective study, there could have been biases during data collection and may not represent the general population [4]. Prevalence of cannabinoid could have been underestimated as urine toxicology in our unit is not universal but risk factor based. There has been five-fold increase in use of opioid nationwide (Table 1).

\begin{tabular}{|l|l|l|l|l|l|}
\hline Year & $\begin{array}{l}\text { Total number of } \\
\text { inborn patients }\end{array}$ & Cocaine & Cannabinoids & Opioids & Other \\
\hline $2005-06$ & 634 & $70(11)$ & $13(2)$ & $34(5.3)$ & $\begin{array}{l}14 \\
(2.2)\end{array}$ \\
\hline $2007-08$ & 508 & $42(8.3)$ & $42(8.3)$ & $31(6.1)$ & $\begin{array}{l}14 \\
(2.7)\end{array}$ \\
\hline $2009-10$ & 575 & $28(4.8)$ & $45(7.8)$ & $33(5.7)$ & $\begin{array}{l}10 \\
(1.7)\end{array}$ \\
\hline $2011-12$ & 667 & $19(2.8)$ & $48(7.2)$ & $34(5.1)$ & $8(1.2)$ \\
\hline $2013-14$ & 648 & $22(3.4)$ & $41(6.3)$ & $28(4.3)$ & $\begin{array}{l}10 \\
(1.5)\end{array}$ \\
\hline
\end{tabular}

Table 1: Trend of use of cocaine, cannabinoid, opioids and other illicit (Benzodiazepines, amphetamines) in our NICU from 2005-2014.

However, such pattern was not observed in our population. Opioid in our population is primarily heroin use or methadone treatment and rarely prescription drug abuse (Figure 1).

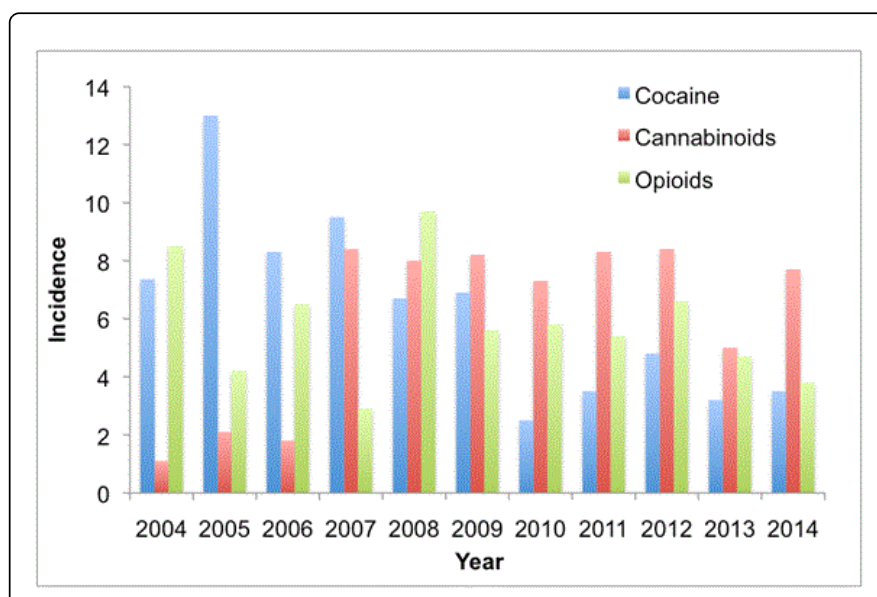

Figure 1: Graphical representation of drug abuse trend.

\section{Conclusion}

The trend in the type of illicit drug use in mothers of infants admitted to our NICU has shifted from predominant cocaine use to predominant marijuana use over the last decade. 
Citation: Joshi S (2017) Changing Trends in the Types of Intrauterine Illicit Drug Exposures in Neonates Admitted to Our Neonatal Intensive Care Unit (NICU). J Gen Pract (Los Angel) 5: 322. doi:10.4172/2329-9126.1000322

Page 2 of 2

\section{References}

1. Slutsker L (1992) Risks associated with cocaine use during pregnancy. Obstet Gynecol 79: 778-789.

2. Patrick SW, Schumacher RE, Benneyworth BD, Krans EE, McAllister JM, et al. (2012) Neonatal abstinence syndrome and associated health care expenditures : United States, 2000-2009. JAMA 307: 1934-1940.
3. Leemaqz SY, Dekker GA, McCowan LM, Kenny LC, Myers JE, et al. (2016) Maternal marijuana use has independent effects on risk for spontaneous preterm birth but not other common late preterm complications. Reprod Toxicol 62 : 77-86.

4. McQueen K (2016) Neonatal abstinence syndrome. N Engl J Med 375: 2468-2479. 